\title{
Pediatric supratentorial intraventricular tumors
}

\author{
Daniel Y. Suh, M.D., Ph.D., And Timothy Mapstone, M.D. \\ Department of Neurosurgery, Emory University School of Medicine, and the Children's Healthcare of \\ Atlanta-Egleston, Atlanta, Georgia
}

\begin{abstract}
A variety of mass lesions can arise within or in proximity to the ventricular system in children. These lesions are relatively uncommon, and they present a unique diagnostic and surgical challenge. The differential diagnosis is determined by tumor location in the ventricular system, clinical presentation, age of the patient, and the imaging characteristics of the lesion. In this report the authors provide an introduction to and an overview of the most common pediatric supratentorial intraventricular tumors. The typical radiographic features of each tumor and location preference within the ventricular system are reviewed. Management and treatment considerations are discussed. Examination of tissue samples to obtain diagnosis is usually required for accurate treatment planning, and resection without adjuvant therapies is often curative. The critical management decision frequently involves determining which lesions are appropriate for surgical therapy. Care ful preoperative neuroimaging is extremely useful in planning surgery. Knowledge of the typical imaging characteristics of these tumors can help to determine the diagnosis with relative certainty when a tissue sample has not been obtained, because a small subset of these lesions can be managed expectantly.
\end{abstract}

\author{
KEY WORDS - intraventricular tumor • pediatric tumor • brain lesion • \\ hydrocephalus
}

One tenth of all CNS neoplasms present within or in proximity to the ventricular system. ${ }^{85}$ These neoplasms comprise a heterogeneous group with regard to tumor type and clinical prognosis in both children and adults. Although some of these tumors are aggressive high-grade lesions, many are histologically benign and potentially curable by undertaking resection. Because they tend to grow slowly, however, they may remain clinically silent and reach significant size before becoming symptomatic, making the excision technically challenging. Typically, these lesions cause symptoms and signs of increased ICP due to hydrocephalus, which will vary depending on the age of the patient. An older child with raised ICP will complain of persistent headache or have episodes of vomiting that characteristically occur in the morning. In the nonverbal child or infant, the only evidence of increased ICP may be nonspecific signs of irritability, loss of appetite, anhedonia, or a finding of macrocrania. Specific focal neurological deficits occur depending on tumor location and involvement of adjacent structures or surrounding cerebral parenchyma.

Specific tumor types appear to occur more frequently in

Abbreviations used in this paper: $\mathrm{CNS}=$ central nervous system; $\mathrm{CPP}=$ choroid plexus papilloma; $\mathrm{CPC}=$ choroid plexus carcinoma; $\mathrm{CSF}=$ cerebrospinal fluid; $\mathrm{CT}=$ computerized tomography; GCT = germ cell tumor; HCG $\beta=$ human chorionic gonadotropin- $\beta ;$ JPA $=$ juvenile pilocytic astrocytoma; $\mathrm{ICP}=$ intracranial pressure $; \mathrm{MR}=$ magnetic resonance NF = neurofibromatosis; PNET $=$ primitive neuroectodermal tumor; SGCA = subependymal giant cell astrocytoma. certain anatomical locations and in certain age groups. ${ }^{61,75}$, 80,85,92,124,133 Table 1 provides a list of common pediatric intraventricular tumors by ventricular location. The imaging characteristics of these lesions are also described in Table 2. ${ }^{75,85,124}$ Although these distinctions may seem arbitrary as most of these tumors occur in patients throughout the ventricular system and across a wide range of ages, tumor location, age of the patient, and imaging characteristics are helpful in determining the differential diagnosis. To make the distinction between intra- and extraventricular lesions also aids in differential diagnosis and guides in planning the surgical approach.

Microsurgical resection has been the treatment of choice for the majority of these lesions. The use of stereotactic navigational systems to assist in volumetric resection of intraventricular tumors has also been described. ${ }^{79}$ Minimally invasive neuroendoscopic techniques used to diagnose and potentially resect intraventricular tumors may ultimately prove to be as effective as microsurgical approaches. ${ }^{38}$ The propensity of intraventricular tumors to reach significant size at presentation as well as the risk of significant bleeding with piecemeal resection, especially in cases of lateral ventricular tumors limit the role of endoscopic techniques to selected cases. Tumor histological type and location as well as the presence and degree of neurological deficit determine the management in the individual patient.

\section{TUMORS OF THE LATERAL VENTRICLES}

Fewer than $1 \%$ of all intracranial neoplasms arise with- 
TABLE 1

Pediatric supratentorial intraventricular neoplasms by location*

\begin{tabular}{|c|c|}
\hline Location & Tumor \\
\hline \multicolumn{2}{|l|}{ lat ventricles } \\
\hline trigone & CPP, ependymoma, meningioma (rare) \\
\hline body & astrocytoma, PNET, teratoma \\
\hline FH/SP & SGCA, PA, PNET \\
\hline \multicolumn{2}{|l|}{ third ventricle } \\
\hline FOM/ant 3rd ventricle & PA, craniopharyngioma, germinoma, CPP (rare), colloid cyst (rare) \\
\hline FOM/pos 3rd ventricle & pineal, high-grade astrocytoma, ependymoma, germ cell \\
\hline
\end{tabular}

in the lateral ventricles, although the incidence of lateral ventricular tumors may be higher in the pediatric population. ${ }^{133}$ One half of all adult intraventricular tumors and one quarter of pediatric tumors occur in the lateral ventricle. ${ }^{91}$ Histological diagnosis varies with both the age of the patient $t^{61,75,80,85,124}$ and the specific location of the lesion within the ventricle itself. ${ }^{75,80,92}$ Data reported in three large series of patients harboring intraventricular masses ${ }^{61,75,80}$ were combined for further analysis. Despite the obvious limitations in these studies, including lack of complete histological data, ${ }^{75}$ lack of inclusion of certain tumor types, the grouping of children and adults, inherent selection biases, and lack of uniformity in determining lesion location, certain obvious trends are apparent. In all three studies, the trigone is the most common site for tumors arising in the lateral ventricles, with rates ranging from 38 to $56 \%$. This finding is consistent with data reported by Piepmeier. ${ }^{92}$ In a series of 22 patients, the author reported the incidence of tumors within the lateral ventricle in descending order of frequency: trigone (50\%), body $(35 \%)$, frontal horn $(10 \%)$, and temporal horn $(5 \%)$. In contrast to the results of Piepmeier, ${ }^{92}$ metaanalysis of the data further suggests that the incidence of tumors occurring in the body of lateral ventricle $(27.6 \%)$ may actually be similar to that of tumors found in the frontal horn $(26.6 \%)$.

In children, intraventricular neoplasms occur more often in the trigone, primarily because certain tumor types that favor the trigonal region have a predilection for occuring in children. Zuccaro, et al., ${ }^{133}$ have examined a series of 54 children and young adults, ranging in age from 15 days to 20 years, with histologically proven lateral ventricular tumors surgically treated over a 10-year period. The trigone and frontal horn were the most common sites of origin (15 [27.8\%]) of 54 patients, followed in order of frequency by posterior horn (six [11\%]), temporal horn (five [9.3\%]), and panventricular or frontotemporooccipi-

TABLE 2

Imaging characteristics of common pediatric supratentorial intraventricular tumors*

\begin{tabular}{|c|c|c|c|c|c|c|c|}
\hline \multirow[b]{2}{*}{ Neoplasm } & \multicolumn{3}{|c|}{ CT Characteristics } & \multicolumn{3}{|c|}{ MR Imaging Characteristics $\uparrow$} & \multirow[b]{2}{*}{ Comment } \\
\hline & Density & Calcified & Enhancement & $\mathrm{T}_{1}$ intensity & $\mathrm{T}_{2}$ intensity & Enhancement & \\
\hline CPP & $\begin{array}{l}\text { iso-hyper } \\
(3 / 4)\end{array}$ & $25 \%$ & +++ & hypo & iso-hyper & + & $\begin{array}{l}\text { trigone in children; all ven- } \\
\text { tricles dilated; may be locally } \\
\text { invasive }\end{array}$ \\
\hline $\mathrm{CPC}$ & iso & $25 \%$ & +++ & hypo & iso-hyper & + & $\begin{array}{l}\text { trigone in children; craniospi- } \\
\text { nal dissemination }\end{array}$ \\
\hline $\begin{array}{l}\text { astrocytoma } \\
\text { (low-grade) }\end{array}$ & iso & $15-20 \%$ & + & hypo & hyper & + & $\begin{array}{l}\text { pilocytic: cystic, mural nodule } \\
\text { may enhance intensely }\end{array}$ \\
\hline SGCA & $\begin{array}{l}\text { mixed (iso- } \\
\text { hypo) }\end{array}$ & common & +++ & hypo-iso & iso-hyper & ++ & $\begin{array}{l}\text { tuberous sclerosis; arise in re- } \\
\text { gion of FOM }\end{array}$ \\
\hline ependymoma & iso & $(50 \%)$ & ++ & hypo & hyper & ++ & $\begin{array}{l}\text { supratentorial ependymomas } \\
\text { arise in trigone, cystic; local } \\
\text { recurrence }\end{array}$ \\
\hline meningioma & hyper & $(20-25 \%)$ & +++ & iso & iso & +++ & $\begin{array}{l}\text { rare in children; cystic; can be } \\
\text { multiple; NF-2 }\end{array}$ \\
\hline PNET & hyper & common & + & hypo & hyper & + to ++ & $\begin{array}{l}\text { neonates and infants; highly } \\
\text { malignant }\end{array}$ \\
\hline central neurocytoma & iso-hyper & yes & ++ & iso & iso-hyper & + to ++ & immunohistochemistry \\
\hline germinoma & hyper & uncommon & +++ & iso-hyper & iso-hypo & + & CSF \& serum tumor markers \\
\hline teratoma & mixed & yes & - & mixed & mixed & - & $\begin{array}{l}\text { heterogeneous \& variable } \\
\text { imaging characteristics }\end{array}$ \\
\hline craniopharyngioma & hyper & $\begin{array}{l}\text { yes }(90 \% \text { rim } \\
\text { calcified) }\end{array}$ & +++ & hypo & hyper & +++ & $\begin{array}{l}\text { cystic: adamantinomatous; } \\
\text { children }>\text { adults; solid: } \\
\text { papillary; adults }>\text { children }\end{array}$ \\
\hline colloid cyst & $\begin{array}{l}\text { iso }(1 / 3) \\
\text { hyper }(2 / 3)\end{array}$ & no & rim & hyper & hypo & rim & $\begin{array}{l}\text { mixed MR signal based on } \\
\text { cyst content }\end{array}$ \\
\hline
\end{tabular}

$*+=$ minimal $++=$ moderate $;+++=$ marked $;-=$ none.

$\uparrow$ Refers to $\mathrm{T}_{1}$ - and $\mathrm{T}_{2}$-weighted images. 
tal (four [7.4\%]). Seventeen percent were bifrontal tumors. The most frequent tumor types were SGCA (14 [25.9]\%); choroid plexus tumors (12 [22.2\%]: nine papillomas [16.7\%] and three carcinomas [3.7\%]); ependymomas (eight [14.8\%]); and astrocytomas (six [11.1\%]).

\section{Trigonal Lesions}

Choroid plexus tumors are one of the most common lesions of the lateral ventricle in young children, and the majority occurs within the trigone. ${ }^{12,61,75,80,133}$ Ependymomas and low-grade astrocytomas (for example, pilocytic astrocytomas and SGCAs) occur in the trigonal region in older children and young adults. Intraventricular meningiomas typically occur in the trigonal region in older adults, although they can arise in children. Two nonneoplastic lesions that frequently present as trigonal lesions are choroid plexus cysts and xanthogranulomas, both of which are benign, typically asymptomatic lesions that occur bilaterally and are found incidentally. The former are epithelial-lined cysts located in the glomus that can be seen in neonates. The latter are choroid plexus masses that typically occur in adults but are occasionally found in children.

Choroid Plexus Papilloma and Carcinoma. Choroid plexus papillomas account for approximately 2 to $5 \%$ of all intracranial neoplasms in children and 10 to $20 \%$ of tumors that occur in the first year of life. ${ }^{30,44}$ Choroid plexus papillomas are the most common lateral ventricular tumor in children, with the vast majority (70-90\%) of these tumors occurring in children younger than 2 years of age. ${ }^{12,65,90}$ In older children and adolescents, these lesions demonstrate a propensity for the fourth ventricle, mirroring the same anatomical preference as that seen in adults. There appears to be a slight male preponderance. Choroid plexus papillomas are histologically benign lesions that may show focal brain invasion. ${ }^{17}$ In one report the authors have described a subset of atypical CPPs that demonstrate local parenchymal invasion and loss of the normal villus architecture at the site of invasion but otherwise have a benign cellular appearance. ${ }^{65}$ This variant of CPP has in the past been diagnosed as a CPC, although these tumors appear to be distinct from CPCs in that gross-total resection without adjuvant therapy may be curative.

Patients with CPPs usually present with signs of hydrocephalus and marked ventricular dilation. In $80 \%$ of cases, ventricular enlargement occurs without obvious evidence of obstruction, implicating CSF overproduction or malabsorption in the pathogenesis. These lesions are iso- to hyperdense on CT scans, hypointense on $\mathrm{T}_{1}$-weighted MR images, and iso- to hyperintense on $\mathrm{T}_{2}$-weighted MR images (Fig. 1). Tumor margins are irregular, mottled masses, reflecting a frondlike surface. Because CPPs are highly vascular lesions, they strongly enhance with contrast administration. Enlarged choroidal arteries are often present, and the lateral posterior choroidal arteries frequently represent the major blood supply. Tumor calcification occurs in $25 \%$ of lesions but is relatively uncommon in lesions found in children.

Complete resection of well-differentiated papillomas is essentially curative, and adjuvant therapies are not needed. $26,30,76,77,90,116$ The critical aspect of the surgical approach is to expose the vascular pedicle during the initial stage of the procedure to avoid avulsion of the feeding arteries, which can occur when manipulating these large lesions. Moreover, attempts to debulk the tumor without control of the vascular pedicle can result in significant blood loss and subsequent morbidity and or mortality. ${ }^{26,90,116}$ For these reasons, microsurgical rather than endoscopic approaches are favored, although small CPPs have been successfully resected using endoscopic techniques. ${ }^{38}$ Preoperative angiographic evaluation and embolization can be extremely useful in cases of highly vascular lesions. Multistaged procedures or the use of specialized equipment such as the argon-beam coagulator have also been proposed by some authors ${ }^{119}$ as necessary in cases of extremely hypervascular tumors; others have argued that multiple subtotal resection procedures only increase the risk of significant perioperative bleeding. ${ }^{74}$ Complete resection may

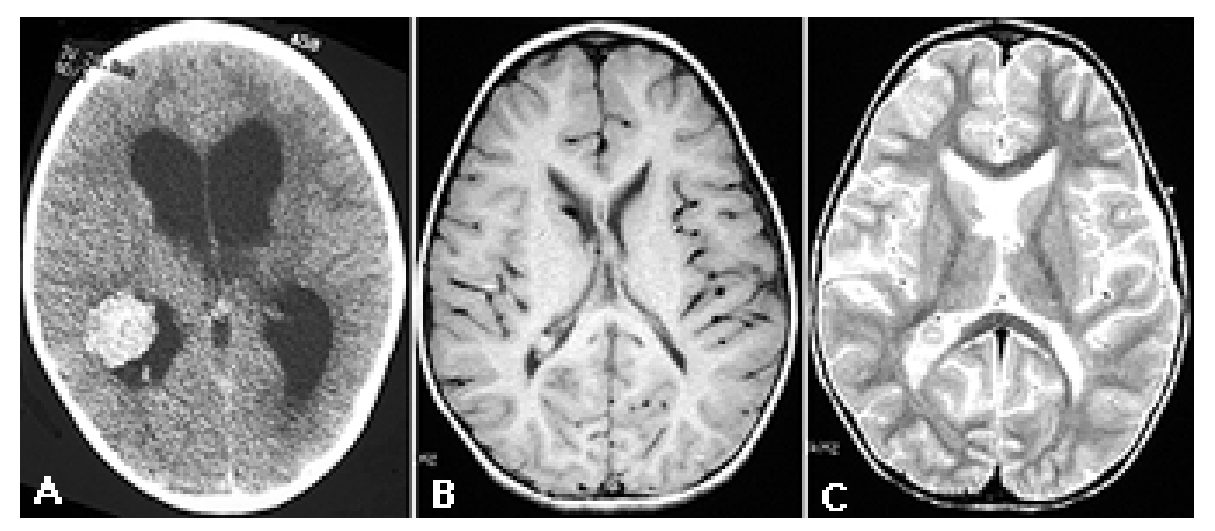

Fig. 1. Imaging studies of CPP. Axial noncontrast CT scan (A) revealing a large right lateral intraventricular mass in the trigonal region with associated hydrocephalus. Axial $\mathrm{T}_{1}-(\mathrm{B})$ and $\mathrm{T}_{2}$-weighted (C) MR images without gadolinum, demonstrating a large intraventricular mass extending from the atrium of the right lateral ventricle to the temporal horn. The mass has lobulated margins and is slightly heterogeneous in signal on both $\mathrm{T}_{1}$ - and $\mathrm{T}_{2}$-weighted sequences with a few small areas of necrosis or cystic change. There are areas of low signal intensity, which likely represent hemorrhage and are best seen on the hemosiderin sequences (not shown). Contrast-enhanced images (not shown) demonstrate a fairly homogeneous enhancement pattern. No remote CSF seeding was seen. 
not eliminate the need for CSF diversion. Resection should be followed by a trial of ventricular drainage, because hydrocephalus may persist even after successful excision necessitating placement of a shunt in up to $50 \%$ of patients. ${ }^{26,90}$ In patients with residual tumor, secondlook surgery has been recommended by some investigators to achieve complete resection. ${ }^{26}$ Finally, a key technical detail following any transcortical resection of an intraventricular and/or paraventricular tumor is the closure of the corticotomy by using biological glue or fibrin adhesive to minimize the risk of postoperative subdural fluid collections. ${ }^{3,52,90}$ Such postoperative collections have been associated with poor outcome following the resection of CPPs. ${ }^{90}$

Choroid plexus carcinomas are uncommon lesions, accounting for approximately one third of choroid plexus neoplasms. ${ }^{116}$ Almost all of these lesions occur in infants and children (2-4 years of age) and arise in the lateral ventricles. Distinguishing between CPP and CPC can sometimes be difficult based on pathological criteria, although immunohistochemistry can help to differentiate between the two. Choroid plexus carcinomas express keratin as a function of their epithelial differentiation but seldom express S-100 protein, glial fibrillary acid protein, or transthyretin, all of which are frequently expressed by CPPs. These lesions demonstrate intraparenchymal infiltration with cellular atypia and conspicuous mitoses. In contrast to the rarity of craniospinal dissemination in CPPs, ${ }^{32}$ craniospinal dissemination is common in CPCs, and, on occasion, these lesions may undergo systemic metastasis. Imaging characteristics can be helpful in distinguishing CPC from CPP. Choroid plexus carcinomas demonstrate heterogeneous enhancement, intraparenchymal invasion, peritumoral parenchymal edema, and evidence of dissemination through the subarachnoid space (Fig. 2).

Total excision is the major predictor of long-term survival in patients with $\mathrm{CPC} ; ;^{9,29,30,42}$ the 5-year survival rates range from 26 to $50 \%$. Because of their invasive nature and propensity to metastasize, however, most CPCs are not amenable to gross-total resection. Moreover, whereas gross-total resection of CPC is associated with the most favorable outcome, it remains unclear whether improved outcome is attributable to resection alone or reflects more favorable tumor biology nature (that is, degree of invasion and/or extent of vascularity). ${ }^{42}$ Although some encouraging results have been reported for postoperative radiotherapy $^{30,133}$ and chemotherapy in patients with CPC, ${ }^{28,42,115}$ the contribution of adjuvant therapies over and above grosstotal resection remains unclear. Postoperative chemotherapy has not been shown to prevent recurrence in these tumors, although postoperative radiotherapy may be effective against recurrence in older children. ${ }^{90}$ In cases in which complete resection is not possible, however, adjuvant chemotherapy following acquisition of a biopsy sample has been used with some success as a preoperative regimen to help improve the chance of gross-total resection at reoperation. ${ }^{116}$ Whether this combination of preoperative chemotherapy followed by resection offers survival benefits comparable with radical resection performed as an initial intervention is not clear.

Ependymoma. Approximately 8 to $13 \%$ of all childhood intracranial neoplasms are ependymomas; ${ }^{49}$ two thirds arise in the posterior fossa, and one third are supratentorial. Supratentorial ependymomas are largely intraor paraventricular masses most commonly associated with the lateral ventricles, but they may also present as isolated third ventricular masses. ${ }^{88}$ Most of them arise in the trigonal region or body of the lateral ventricle. ${ }^{61,75,133}$ On CT scans, ependymomas appear to be solid masses, isodense to hyperdense to brain, with variable enhancement after contrast administration. Supratentorial ependymomas are often associated with a cyst, although the cystic nature of these lesions does not appear to confer benign histology. ${ }^{20}$ Magnetic resonance studies demonstrate heterogeneous
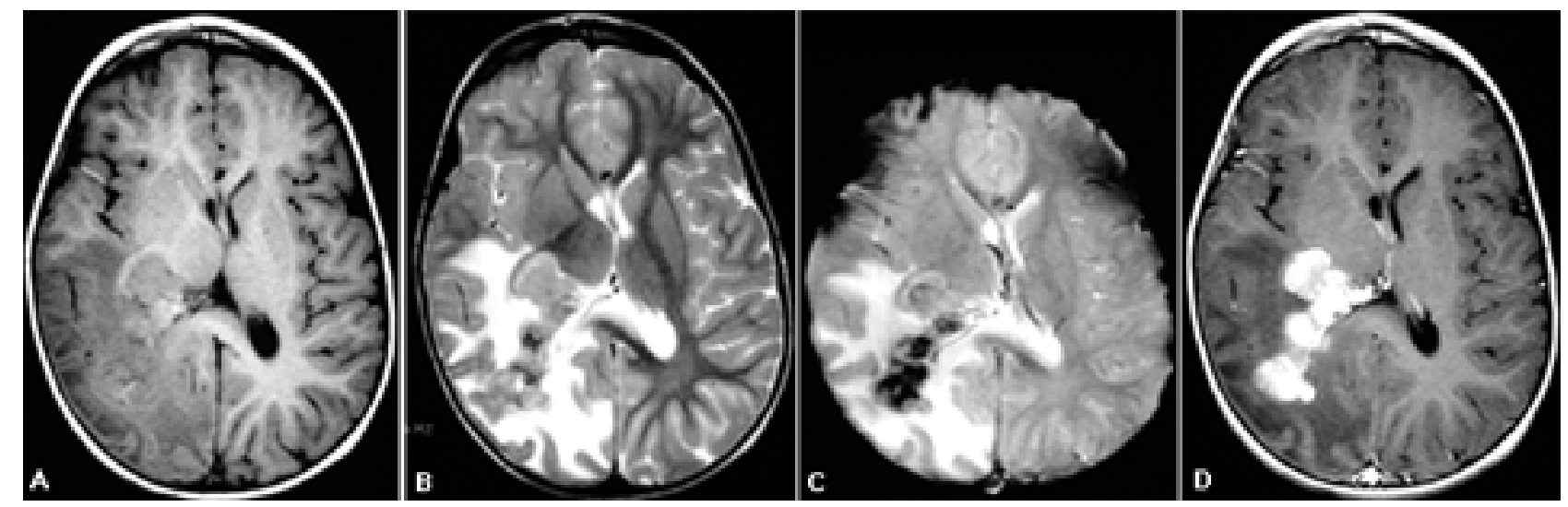

Fig. 2. Magnetic resonance imaging studies of CPC. Axial $\mathrm{T}_{1}-(\mathrm{A})$ and $\mathrm{T}_{2}$-weighted (B) precontrast MR images demonstrating a lobulated mixed signal intensity mass that appears to arise in the atrium of the right lateral ventricle. The choroid plexus appears to be the site of origin. The tumor extends into the parietal lobe white matter. There is also extension peripherally into the subcortical region. Extensive vasogenic edema in the right parietal, occipital, and posterior temporal lobes is noted. Edema also extends into the external capsule on the right. There is mass effect with distortion of the right thalamus and brainstem with effacement of the right perimesencephalic cistern. No hydrocephalus is seen. Axial hemosiderin-sequence MR image (C) demonstrating an area of low signal intensity, suggesting the presence of blood products. Axial $\mathrm{T}_{1}$-weighted MR scan with gadolinum (D) revealing marked enhancement. A prominent vessel is noted coursing through the posterior temporal lobe toward the lesion, which likely represents a feeding or draining vessel. 
signal intensity on $\mathrm{T}_{1}$ - and $\mathrm{T}_{2}$-weighted images with heterogeneous enhancement. These lesions are frequently calcified.

The prognostic implications of histological grading of ependymomas remain controversial, as little consensus has been reached on the value of specific histological features. Although highly cellular lesions with evidence of cellular atypia, abundant mitotic activity, and vascular proliferation suggest a higher propensity to recur, the presence of cellular atypia in isolation or the presence of necrosis does not appear to confer increased risk for recurrence. These lesions may recur even after an apparent macroscopically complete removal at the time of surgery.

Because of the risk of recurrence, adjuvant therapies have been performed in children regardless of the extent of resection. Local recurrence represents the major pattern of tumor recurrence. ${ }^{50,55}$ Management strategies have traditionally involved postoperative radiotherapy, although there has been a growing trend for the inclusion of chemotherapies. Whereas the beneficial effect of radiotherapy on survival has been documented, ${ }^{86,126,130}$ the specific role of radiotherapy in the treatment of intracranial ependymomas in children is debated. ${ }^{40,50,78}$ Conventional radiotherapy, when combined with resection of intracranial ependymomas, has resulted in improved 5-year survival and 5-year progression-free survival rates. ${ }^{41,84,93,108} \mathrm{Be}$ cause of the long-term sequelae associated with conventional radiotherapy, however, most pediatric centers have significantly limited the extent of its use in the treatment of the young child. The authors of a recent preliminary study investigating the role of postoperative radiosurgery in patients with intracranial ependymomas did not find a significant benefit with regard to prevention of long-term recurrence. ${ }^{95}$ Similarly, the utility of chemotherapy in the management of intracranial ependymomas remains equivocal, as there is little evidence demonstrating improvement in survival rates. ${ }^{11,55,120}$

Despite improvements in progression-free and overall survival rates reported in recent series, the overall prognosis remains relatively poor for children with intracranial ependymomas. Mounting evidence, however, suggests that supratentorial ependymomas may represent a subgroup of intracranial ependymomas with different prognostic implications than their infratentorial counterparts. Complete resection of intracranial ependymomas without further therapies has been associated with improved longterm tumor-free survival. 5,55,56,60,69,78,83,88,94,100,120 Although some authors have noted that supratentorial ependymomas have a poorer prognosis compared with their posterior fossa counterpart, ${ }^{60}$ other authors have noted that total resection is more often achieved in patients with supratentorial as opposed to infratentorial ependymomas, $, 33,87$, 88,100 especially in cases of lateral ventricular tumors or extraventricular tumors located far from eloquent cortex. ${ }^{33,87}$ It has also been noted that complete resection without adjuvant therapy represents a viable option in the treatment of supratentorial ependymomas. ${ }^{5,56}$ In a cooperative study published by the Children's Cancer Group, total resection was achieved in $64 \%$ of cases of supratentorial ependymomas as opposed to $38 \%$ of infratentorial ependymomas. Radical resection and the extent of residual tumor demonstrated on postoperative imaging were the only significant prognostic factors. ${ }^{100}$ Radical surgery alone appears to be a viable option as an initial treatment when postoperative imaging clearly confirms the absence of residual tumor. ${ }^{5,48,88,100}$ According to Palma, et al. ${ }^{88}$ surveillance imaging should be conducted every 4 to 6 months, with the duration of monitoring based on the child's age at the time of surgery and continued until the child exceeds the period of risk of recurrence according to Collins' law (patient age at diagnosis +9 months). ${ }^{13} \mathrm{~A}$ second-look operation with the goal of total resection should be considered in cases in which local recurrence is found. In children older than 3 years of age, radiotherapy is used in cases of inoperable or partially resected tumor, malignant ependymomas, or following a second tumor resection for recurrence. ${ }^{50,88}$ Spinal and craniospinal radiotherapy is undertaken in children older than 3 years of age in whom there is documented disseminated disease. For children younger than 3 years of age in whom residual tumor has been documented after initial resection, chemotherapy can be administered and radiotherapy deferred until the child is older. ${ }^{50}$

Meningiomas. Intracranial meningiomas are relatively rare in children, accounting for less than $2 \%$ of all intracranial neoplasms in this population. ${ }^{34,54,71}$ Meningiomas that occur in children differ in many respects from those in adults. In the pediatric population, intracranial meningiomas are more likely to be intraventricular and cystic, ${ }^{8,34,125}$ malignant, ${ }^{22}$ and demonstrate multiplicity. ${ }^{24} \mathrm{Neu}-$ rofibromatosis Type 2 should be considered in the young patient with an intracranial meningioma, especially in the setting of multiple lesions. The female predominance noted in adults is not observed in children. ${ }^{71}$ When meningiomas occur in the older child or adolescent, they also tend to be supratentorial in origin and intraventricular in location, but clinically they demonstrate an affinity for behaving like those found in adults. The atrium of the lateral ventricle is the most common intraventricular location. ${ }^{22,51}$ In fact, meningioma is the most common in the trigonal demonstrated mass after the first decade of life.

Patients with intracranial meningiomas typically present with signs of hydrocephalus. Because of their affinity for the trigone, these lesions can cause atypical psychomotor or temporal lobe seizures. Intraventricular meningiomas are well-circumscribed, lobulated masses that are typically hyperdense on CT scans and isointense with brain on $\mathrm{T}_{1}$-weighted MR images. Nearly all enhance intensely after contrast administration. Calcifications are often noted. Complete resection is most often curative. The treatment of subtotally resected meningiomas in children remains controversial, especially in the setting of NF. ${ }^{8}$ Incomplete excision, the presence of a focal neurological deficit at the time of diagnosis, and malignant histology have been associated with poor outcome. ${ }^{71}$ As with other neoplasms located in the lateral ventricle, significant blood loss can occur when these tumors are manipulated during the surgical exposure. Preoperative angiography and embolization should be considered in selected cases.

\section{Body of the Lateral Ventricle}

In the young child, intraventricular masses that involve the body of the lateral ventricle include astrocytoma, PNET, and teratoma. Most of these lesions arise from ependymal and subependymal tissue surrounding the ven- 
tricle and extend into the low-resistance ventricular cavity. In older children anaplastic astrocytoma with intraventricular extension is the most common ventricular tumor involving the frontal horn or ventricular body.

Astrocytoma. Astrocytomas account for approximately $35 \%$ of all brain tumors in children. The most malignant forms occur supratentorially, as opposed to the benign varieties, which are more commonly seen infratentorially. Lateral ventricular astrocytomas typically arise from extraventricular structures that are located adjacent to the ventricle. The thalamus is a common site of origin for astrocytic tumors that expand into the ventricle. As such, there can be relatively little intraparenchymal displacement, even with large tumors. Children with malignant astrocytomas tend to fare better in terms of outcome than adult with malignant astrocytomas. This is likely a reflection of the larger portion of anaplastic astrocytomas and the smaller number of glioblastomas multiforme that occur in children. The most common histological types include fibrillary astrocytoma, JPA, and SGCA.

Fibrillary astrocytomas may be diffuse and infiltrative, or they may be more circumscribed and noninfiltrative. They may extend within the corpus callosum to involve both hemispheres. The more infiltrative lesions are observed to be hypodense on CT scans and do not enhance. These tumors are rarely associated with peritumoral edema. Calcifications are present in $20 \%$ of cases. On MR imaging, more infiltrative lesions demonstrate mildly decreased signal intensity on $\mathrm{T}_{1}$ - and hyperintensity on $\mathrm{T}_{2}$ weighted images. Focal lesions have more well-defined hypointensity on $\mathrm{T}_{1}$ - and hyperintensity on $\mathrm{T}_{2}$-weighted images. These masses typically do not enhance, although mild enhancement can be seen (Fig. 3).

Juvenile pilocytic astrocytomas most often occur infratentorially and have a distinct predilection for the cerebellum. These tumors are found supratentorially in $11 \%$ of children with intracranial neoplasms and demonstrate a preference for the opticohypothalamic region. Less frequently, JPAs involve the anterior body of the lateral ventricle and rostral third ventricle. ${ }^{37,61,63}$ Intraventricular
JPAs are rarely found in the trigone. ${ }^{114}$ Radiographically, JPAs are usually well-circumscribed solid lesions with a cystic component that contains a mural nodule. These lesions demonstrate low signal intensity on $\mathrm{T}_{1}$-weighted MR images and enhancement with contrast, which can help to distinguish them from diffuse astrocytomas or well-differentiated fibrillary astrocytomas. In adults, lateral ventricular astrocytomas are more likely to be highergrade tumors with heterogeneous signal, associated peritumoral edema, and enhancement after administration of contrast material.

Treatment is determined by histological grade, lesion location, imaging characteristics, patient age, and clinical presentation. High-grade lesions are treated with radioand/or chemotherapy. In terms of low-grade gliomas, most authors agree that completely microscopically resected JPAs do not require further therapy. Recurrence-free survival without adjuvant therapies has been reported to approach nearly $100 \% .{ }^{37,127}$ Therefore, total resection is recommended for JPAs when technically feasible. Regardless of location, however, the natural history of JPA is one of slow, indolent growth, and many physicians will manage these tumors expectantly, especially in cases of tumors involving the optic pathways ${ }^{95}$ or in children with NF1.

The treatment of subtotally resected JPAs or low-grade gliomas remains controversial. The 10-year survival rates of nearly $75 \%$ following subtotal resection or biopsy sampling ${ }^{37}$ have prompted some authors to recommend limited surgery and adjuvant therapies in cases of lesions in which total resection is associated with a high morbidity rate. ${ }^{121}$ Others defer the use of adjuvant therapies following subtotal resection until there is evidence of disease progression. ${ }^{19,89,127}$ Mamelak, et al., ${ }^{72}$ have recommended that children older than 5 years of age in whom low-grade gliomas were subtotally resected undergo focal radiotherapy and that both chemo- and radiotherapy be given if neuraxis dissemination is discovered. These authors further noted a risk for multicentric disease in some patients with JPAs, especially with tumors involving the hypothalamic region. The role of radiotherapy in the treatment of
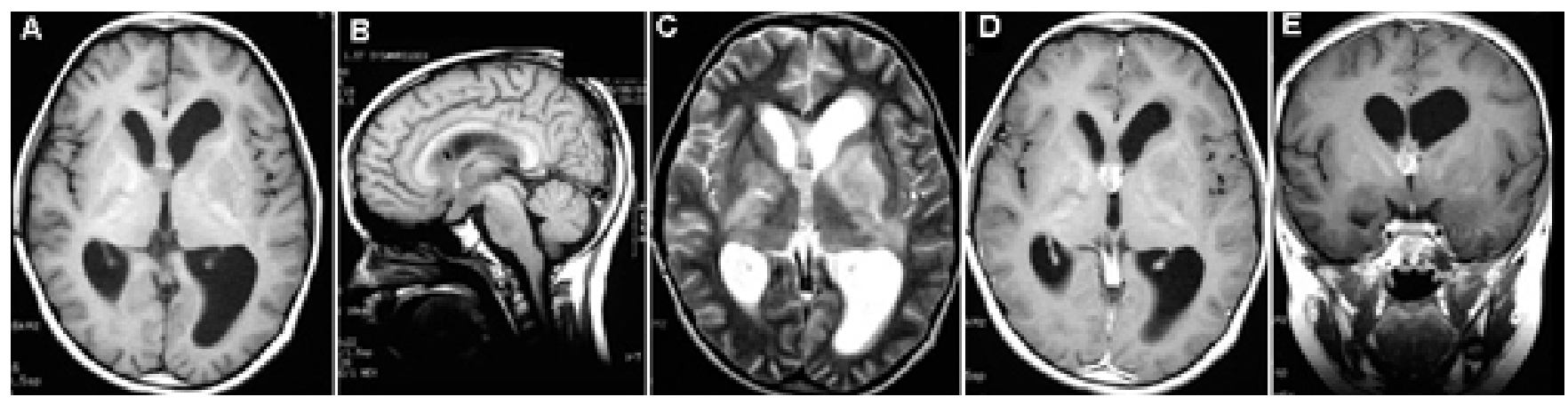

Fig. 3. Magnetic resonance imaging studies demonstrating diffusely infiltrating astrocytoma with an exophytic component at the foramen of Monro. Prior to this study, the patient had undergone placement of a right frontal ventricular catheter for treatment of hydrocephalus. Axial (A) and sagittal (B) $\mathrm{T}_{1}$-weighted images revealing a diffusely infiltrating lesion involving the brainstem and thalamus. Axial (C) $\mathrm{T}_{2}$-weighted images demonstrating extensive hyperintensity in the entire pons, ventral and mid-portion of the midbrain bilaterally, and bilateral involvement of the thalami and striate nuclei, optic chiasm, intracranial optic nerves, and hypothalamus. Axial (D) and coronal (E) $\mathrm{T}_{1}$-weighted gadolinumenhanced images revealing relatively little abnormal enhancement. There is, however, a nodular soft-tissue enhancing lesion at the foramen of Monro. 
progressive low-grade gliomas is not clear in terms of long-term survival. A growing body of evidence suggests that chemotherapy may delay disease progression of lowgrade gliomas, thereby obviating or delaying the need for radiotherapy or radical resection. ${ }^{98}$ Chemotherapy should be strongly considered in young children with evidence of a progressive low-grade glioma that is not amenable to complete resection.

Although the overall survival for patients with JPAs is quite favorable, even when the tumors are incompletely resected, clearly not all low-grade gliomas behave in a clinically benign fashion. Up to one third of JPAs behave aggressively. ${ }^{117}$ These tumors can disseminate to the neuraxis on rare occasions or undergo malignant transformation at the time of progression. ${ }^{14,19,72}$ Some low-grade gliomas appear to progress erratically and do not adhere to Collins' law, making treatment planning difficult. ${ }^{98}$

Primitive Neuroectodermal Tumor. The term PNET represents a group of small cell embryonal tumors of the CNS that exhibit divergent differentiation. Although histologically similar, these tumors are not equivalent and their histogenesis remains undetermined. Supratentorial PNETs are highly malignant in infants and young children, and they account for approximately 2 to $3 \%$ of all childhood brain tumors. ${ }^{39}$ Despite the rarity of these lesions, they represent the most common congenital brain tumor. At least $80 \%$ occur in the first decade of life, usually before the age of 5 years, with many presenting before 1 year of age. Most PNETs are paraventricular masses, located in the deep white matter of the frontal or parietal lobes. The lesions that are intraventricular often involve the body of the lateral ventricle and can reach significant size at the time of presentation. These tumors are large, bulky hemispheric masses that appear well circumscribed on imaging studies. Children typically present with signs of increased ICP, and CSF dissemination can occur. ${ }^{2}$ Radical excision is the preferred treatment along with craniospinal radio- and chemotherapy as adjuvant therapies. The prognosis is generally poor but appears variable. Nonpineal supratentorial PNETs respond differently to treatment than pineal supratentorial PNETs, especially in infants. Encouraging results from the Children's Cancer Group infant study indicate that a significant percentage of patients may be successfully treated with surgery and chemotherapy alone. ${ }^{2}$ Multimodal therapies such as resection followed by craniospinal irradiation with a boost to the tumor site and adjuvant chemotherapy are recommended in older children. ${ }^{58}$

Teratoma. Intracranial germ cell tumors typically arise in the midline, usually in the pineal or suprasellar region, although some may originate more laterally in the thalamus or basal ganglia and extend into the ventricle. These lesions are composed of elements from all three germinal layers. Although teratomas are relatively rare intracranial neoplasms, their incidence increases in patients younger than 15 years of age. These lesions are the most commonly diagnosed hemispheric tumor in the neonate or infant and the most common intracranial neoplasm in stillborn babies and neonates. ${ }^{57}$ Teratomas can arise at any site within the craniospinal axis. Fifty percent of teratomatous lesions present in the posterior third ventricle, accounting for $15 \%$ of pineal regions masses, the remainder occur in the suprasellar region or intraventricularly in the body of the lateral ventricles. Histologically, they are divided into mature or immature types based on the degree of differentiation of the components. Imaging findings are variable, with heterogeneous signal characteristics observed on MR images. Because of their circumscribed nature, mature teratomas and, at times, malignant teratomas are amenable to complete resection and cure. Radiotherapy is not effective for unresected tumors. ${ }^{128}$

\section{Frontal Horn and Foramen of Monro}

Primary septal neoplasms are uncommon. Thickening of the septum pellucidum greater than $3 \mathrm{~mm}$ is suggestive of an infiltrating neoplasm, most commonly an astrocytoma. Dysplastic thickening of the septum can be seen in patients with NF1. Dysembryoplastic epithelial tumorlike lesions of the septum pellucidum have been described in children and young adults. ${ }^{6}$ These lesions are often misdiagnosed as gliomas, but they are clinically, radiographically, and histologically benign tumors. In the young child, the most common intraventricular tumors located within the frontal horn at or near the foramen of Monro include SGCA, choroid plexus neoplasms, and central neurocytomas.

Subependymal Giant Cell Astrocytoma. These lesions are astrocytic-like variants found almost exclusively in patients with tuberous sclerosis. Subependymal giant cell astrocytomas are discovered in 10 to $15 \%$ of patients with tuberous sclerosis. ${ }^{81,109}$ Isolated or spontaneous formes frustes cases of SGCA have also been described. These tumors are low-grade, indolent, and calcified nodular subependymal lesions that usually arise in the foramen of Monro, with an associated soft-tissue mass located within the frontal horn of the lateral ventricle. Although they are mainly found in the regions of the foramen of Monro and frontal horn, subependymal hamartomatous lesions can occur anywhere along the ventricular system. Subependymal hamartomatous nodules along the caudothalamic groove or along the walls of the lateral ventricles are demonstrated in up to $90 \%$ of patients with tuberous sclerosis. Only 2 to $14 \%$ of children with subependymal nodules will develop tumors. ${ }^{109}$ Symptomatic lesions are typically restricted to the region of the foramen of Monro, overlying the head of the caudate nucleus, and are associated with increased ICP from hydrocephalus secondary to foraminal obstruction. Symptomatic SGCAs tend to present before the patient is 20 years of age. Histologically, these tumors are variable but tend to be characterized by large, bizarre-looking astrocytes. They grow progressively and, on rare occasions, demonstrate malignant transformation to glioblastoma. Frequently the diagnosis is guided by the clinical and radiographic features. These tumors demonstrate mixed density or isodensity on CT scans, with variable areas of calcifications. They demonstrate intense enhancement after contrast administration. On MR imaging, the calcified subependymal tubers are hypointense on $\mathrm{T}_{1}$ - and $\mathrm{T}_{2}$-weighted images. The soft tissue component has heterogeneous signal intensity on $\mathrm{T}_{1}$ - and $\mathrm{T}_{2}$-weighted images with intense enhancement after contrast administration (Fig. 4).

Treatment is usually limited to resection and there is excellent long-term survival, ${ }^{25,102}$ although mortality rates 

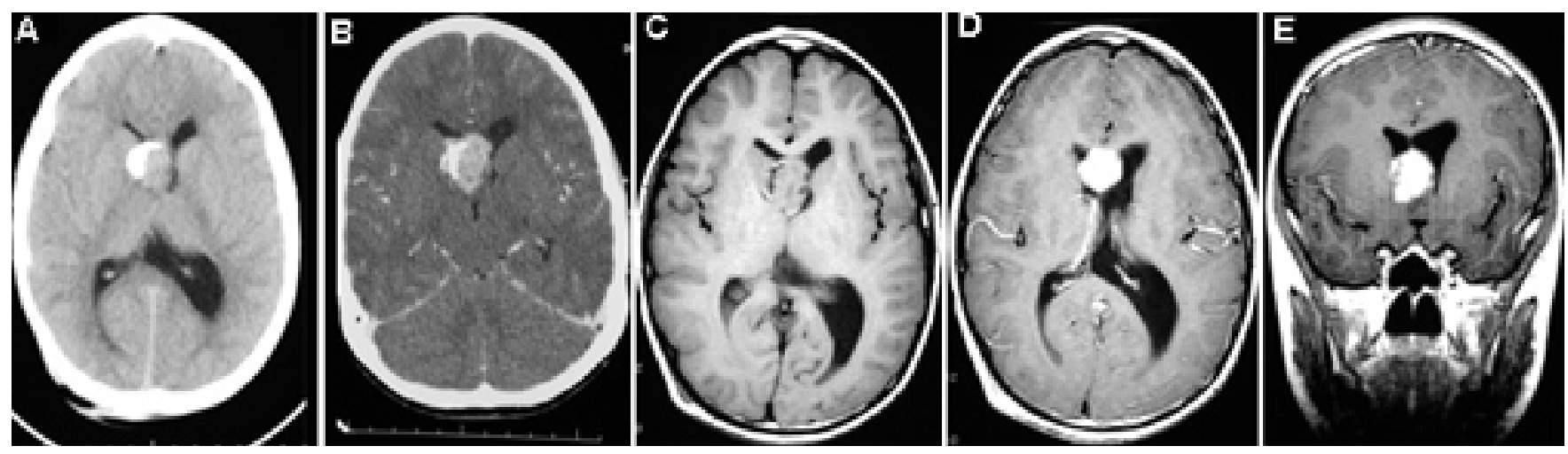

Fig. 4. Imaging studies of SGCA involving both frontal lobes obtained in a 10-month-old girl with tuberous sclerosis. Axial CT scans without (A) and with (B) contrast demonstrating an intraventricular mass with associated hydrocephalus. The mass is calcified along the right margin. Axial (C) $\mathrm{T}_{1}$-weighted MR image revealing that the mass involves both lateral ventricles, slightly more eccentric to the right. The mass is heterogeneous with low signal intensity noted in areas of known calcification along the right side of the lesion and within small cystic or necrotic areas along the left side of the lesion. The mass abuts and distorts the foramen of Monro greater on the right than left, and is intimately associated with the septum pellucidum and the caudate nucleus, anterior thalamus, and caudothalamic groove on the right side. The chiasm does not appear to be involved, and the optic nerves and tracts are of normal size. Axial (D) and coronal (E) $\mathrm{T}_{1}$-weighted gadolinum-enhanced MR images revealing extensive enhancement. No CSF seeding or remote intraventricular dissemination is appreciated.

as high as $10 \%$ have been reported in those children who present acutely and require emergency surgery. ${ }^{82}$ Nabbout, et al. ${ }^{81}$ have determined a number of radiographic characteristics that may help to differentiate presymptomatic SGCAs with the potential for growth from subependymal nodules without growth potential in patients with tuberous sclerosis. According to these authors, subependymal nodules that were localized near the foramen of Monro and measured greater than $5 \mathrm{~mm}$, were incompletely calcified or noncalcified, or enhanced with gadolinum carried the highest risk for tumor growth. These findings were noted as early as 1 year of age, prompting these authors to recommend sequential MR imaging at the time of diagnosis and/or by 2 years of age. If suspicious nodules are identified, MR imaging should be performed annually until the patient reaches the age of 10 years, especially in families with a history of tuberous sclerosis.

Central Neurocytoma. These discrete intraventricular tumors arise at the inferior septum pellucidum near the foramen of Monro where they obstruct the flow of CSF and cause symptoms of increased ICP. Most of these lesions occur in young to middle-aged adults. Noncentral neurocytomas have also been described, either arising in the spinal cord or within the cerebral parenchyma. ${ }^{107,123}$ Histologically, they were often thought to be oligodendrogliomas, and only recently have they been better documented and characterized. The pathological diagnosis is greatly aided by immunohistochemistry, which shows neuronal markers. These tumors are strongly positive for neuron-specific enolase and synaptophysin. The radiological characteristics of these tumors are relatively nonspecific. They appear to be well circumscribed and have heterogeneous density and signal on CT or MR imaging. Enhancement is also variable. Many central neurocytomas are calcified. Total resection is potentially curative. Recurrence does occur in subtotally resected lesions, although the rate of regrowth is typically slow. Moreover, despite their benign histology, they may disseminate through the craniospinal axis, although this rarely occurs. ${ }^{31}$ Atypical neurocytomas with malignant or aggressive features have also been reported. ${ }^{4}$ Although radiotherapy has been performed in patients with subtotally resected tumors, the benefit to overall survival has not been established for those with typical central neurocytoma. ${ }^{62}$ Postoperative radiotherapy may be of benefit in selected patients inwhom there are residual tumors that demonstrate either atypical or malignant characteristics. ${ }^{4}$ In general, the overall prognosis is excellent.

\section{TUMORS OF THE THIRD VENTRICLE}

Primary third ventricular neoplasms are relatively rare regardless of patient age. The vast majority of neoplasms that involve the third ventricle are astrocytomas originating in the wall or the floor of the ventricle and affecting the ventricle by direct extension. Most are low-grade lesions and cause symptoms associated with increased hydrocephalus-induced ICP. Endocrinological deficits and visual disturbances are typically uncommon with tumors arising from within the third ventricle. When visual disturbance is demonstrated, it is usually secondary to extraventricular involvement or optic pathway compression due to ventricular distortion. Mass effect on the hypothalamus or hypothalamic involvement can result in the diencephalic syndrome, which is classically seen in infants and is manifest by emaciation combined with hyperalertness. Lesions located in the posterior segment of the third ventricle can result in mass effect on the pretectal region and/or obstruction of CSF flow.

A variety of tumors can occur in the third ventricle in children, with certain masses more commonly found in the anterior portion compared with the posterior portion of the third ventricle. The more common anterior third ventricular neoplasms are hypothalamic astrocytoma and suprasellar craniopharyngioma. Choroid plexus papilloma, germinoma, teratoma, and ependymoma occasionally are 
seen in children. Ten percent of CPPs involve the third ventricle and occur primarily in children younger than 5 years of age. Fifteen percent of all supratentorial ependymomas present within the third ventricle. Epidermoid and dermoid tumors occur uncommonly in the anterior third ventricle.

A number of nonneoplastic entities that occur in the anterior body of the third ventricle deserve mention. Colloid cysts represent the most common anterior third ventricular mass demonstrated in adults. These lesions can occur in adolescents and young adults but seldom occur in young children. Both microsurgical and endoscopic procedures have been performed to resect these lesions, and the results have been good. Histiocytosis represents a common anterior third ventricular mass lesion found in children; these lesions tend to arise in the suprasellar region from the floor of the third ventricle and may invade the hypothalamus. Children with these lesions can present with evidence of pituitary-hypothalamic dysfunction and bony skeletal lesions. There appears to be a slight male predominance. The goal of surgical intervention is primarily to obtain a biopsy sample to determine a diagnosis, as these lesions are extremely radiosensitive. Cysticercosis is the most common parasitic infection involving the CNS; it is caused by the intestinal tapeworm Taenia solium and is endemic in some areas of Mexico and certain Third World countries. In the United States, cysticercosis is a rare entity more commonly found in the Western and Southwestern regions. The favored location of cystic lesions is either meningeal or within brain parenchyma. Approximately 12 to $18 \%$ are located intraventricularly, possibly gaining access via the choroid plexus. Ventricular involvement is associated with higher patient morbidity and mortality. Cysts may travel via the ventricular system and can cause obstructive hydrocephalus, although the classic clinical presentation in children involves repeated bouts of meningitis rather than hydrocephalus. Treatment of intraventricular cysticercal cysts typically involves three possible options: antihelmintic therapy, CSF diversion, and/or resection of the cysts. Surgery may be necessary to establish a diagnosis or to treat intraventricular lesions that appear to be less responsive to medical therapy. Cerebrospinal fluid diversion for symptomatic hydrocephalus is frequently necessary. Endoscopic management of intraventricular cysticercal cysts, used in combination with third ventriculostomy or septum pellucidotomy in selected cases, has also been described. ${ }^{10}$

\section{Anterior Third Ventricular Masses}

Juvenile Pilocytic Astrocytoma. Juvenile pilocytic astrocytomas represent 5 to $10 \%$ of all cerebral gliomas and account for approximately one third of glial neoplasms occuring in children. The majority of JPAs are supratentorial, arising from the floor of the third ventricle in the chiasmal-hypothalamic region and extending into the third ventricle. Approximately one third of JPAs are infratentorial, located in the cerebellar vermis or hemispheres. Opticochiasmatic-hypothalamic JPAs are one of the most common supratentorial neoplasms in childhood, with nearly $75 \%$ of optic pathway JPAs presenting in patients younger than 12 years of age. ${ }^{101}$ Low-grade gliomas are usually indolent, slow-growing neoplasms with symptom presentation and natural history dependent on location. Although these lesions appear macroscopically well defined, they usually infiltrate the optic pathways and hypothalamus. Some of these tumors, however, progress more rapidly or disseminate to the neuraxis. This is especially true for low-grade gliomas involving the hypothalamus and chiasm. ${ }^{59,72}$

Multicentric pilocytic tumors of the optic nerve are particularly common in patients with NF1. As many as 70\% of optic pathway tumors are pilocytic astrocytomas associated with NF1. ${ }^{67}$ These tumors tend to be very low grade and have a more benign course with favorable prognosis. ${ }^{103}$ In a longitudinal study the authors documented that in children with NF1 and isolated optic nerve gliomas disease progression tended not to occur. ${ }^{66}$ In fact, a case of spontaneous regression of an optic glioma in a child with NF1 has been reported. ${ }^{15}$

In children in whom the bulk of the tumor occupies the ventricle, the most common clinical presentation involves symptoms of hydrocephalus, but visual disturbance is seldom a predominant complaint. Endocrinological and/or hypothalamic dysfunction tend to occur late in the disease process. In contrast to their cerebellar counterparts, which tend to be cystic masses with a mural nodule, opticochiasmatic-hypothalamic JPAs are usually solid lesions and rarely have associated cysts. Radiographically, they appear iso- to hypodense to brain on CT scans, iso- to hypointense on $\mathrm{T}_{1}$-weighted MR images, and hyperintense on $\mathrm{T}_{2}$-weighted MR images. These tumors show mild to moderate enhancement with contrast. Treatment is reserved for symptomatic patients, and observation is often recommended especially for children with NF1.

Craniopharyngioma. Craniopharyngiomas represent the most common nonglial neoplasms in children, accounting for 1 to $2 \%$ of all intracranial neoplasms and nearly $50 \%$ of all suprasellar masses in children. The peak incidence of craniopharyngiomas occurs when the patient is between 5 and 10 years of age. There is a second, smaller peak incidence noted between the fifth and sixth decades. ${ }^{53}$ Lesions that involve the third ventricle primarily arise extraventricularly along the infundibular stalk or in the floor of the anterior portion of the third ventricle with ventricular extension. Purely intraventricular craniopharyngiomas are rare, however, with fewer than 30 pediatric cases reported in a recent review. ${ }^{70}$ The clinical presentation typically involves a combination of symptoms of raised ICP or manifestations of visual, hypothalamic, or endocrinological dysfunction.

The majority of third ventricular CPs appears to be of the papillary type and accounts for approximately $10 \%$ of all craniopharyngiomas. The classic adamantinomatous lesion is typically found in the suprasellar region. The two variants of craniopharyngioma are not only distinct in terms of their morphological features, but also in their age-related incidence, location, radiographic appearance, and prognosis. Papillary craniopharyngiomas are solid, noncalcified masses that are seldom cystic and are more frequently encountered in adults. A dissection plane that separates papillary tumor from the surrounding brain tissue allows for total excision. ${ }^{1,21}$ In a review of the Mayo Clinic experience, Duff, et al., ${ }^{27}$ found no difference in outcome or recurrence rates between papillary and adam- 
antinomatous tumors. Thus, even though craniopharyngiomas are well circumscribed, they are not encapsulated. Moreover, they tend to become insinuated among and adherent to vital neurovascular structures, making radical resection extremely difficult. This adhesiveness to surrounding neural and vascular structures is a risk factor for poor outcome and/or tumor recurrence. ${ }^{23,27}$ Adamantinomatous craniopharyngiomas are more commonly seen in children and tend to be cystic, calcified, suprasellar lesions that are more likely to recur. On MR imaging these lesions have the most heterogeneous signal characteristics of all sellar region masses. The signal is highly variable and dependent on the cyst contents. Craniopharyngiomas enhance strongly but heterogeneously after contrast administration (Fig. 5).

Treatment of these histologically benign but locally aggressive lesions remains controversial. Radical resection has been the mainstay of treatment. Early enthusiasm for radical surgical approaches, however, has been dampened by the recognition that aggressive resection (particularly for retrochiasmatic and giant craniopharyngiomas) was frequently associated with significant morbidity and a relatively high rate of recurrence. ${ }^{23,35,53,96,122,131}$ Therefore, efforts have been focused on combining less aggressive resection with adjuvant therapies as a primary treatment, and the reported results are comparable with those of radical resection. ${ }^{23,36,43,97,106,129}$ Others have advocated a staged surgical approach and the early incorporation of conservative measures such as stereotactically guided cyst aspiration/instillations as a strategy to defer the undertaking of external fractionated radiotherapy until a child is old enough. ${ }^{23,47}$ The ultimate role of stereotactic radiosurgery for these lesions is currently undefined but appears promising. ${ }^{18,68,95}$

Germinoma. Pure germinomas are the most common primary CNS GCT, accounting for $65 \%$ of all CNS GCTs. ${ }^{128}$ Although they occur more often in the pineal region, however, suprasellar germinomas can also present in the anterior third ventricle via extension from the in- fundibular stalk. Occasionally, there is a synchronous pineal region tumor. ${ }^{118}$ In rare cases, these tumors arise in the thalamus or basal ganglia. There is a strong male predominance, with most patients presenting between the ages of 10 and 30 years for germinomas involving the pineal region. ${ }^{64}$ Both pineal and suprasellar region germinomas occur during the first three decades of life and more often at the onset of puberty. Symptoms depend on the site of growth and the degree of invasion of adjacent structures. Patients with anterior third ventricular germinoma generally present with visual loss, decreased libido, and diabetes insipidus. Diffuse ependymal and subarachnoid seeding is common. Computerized tomography scanning typically reveals a hyperdense lesion. On MR imaging, germinomas tend to be isointense on $\mathrm{T}_{1}-$ and $\mathrm{T}_{2}-$ weighted images. They demonstrate homogeneous enhancement after contrast administration.

Because management of CNS GCTs is complicated by the diversity of histological subtypes, accurate diagnosis is paramount to determining the optimal treatment strategy. One key factor is to differentiate pure germinomas from those GCTs that contain an admixture of nongerminomatous elements (choriocarcinoma, endodermal sinus tumor, or embryonal carcinoma). Collectively, the mixed forms are less responsive to adjuvant therapies than pure germinomas. ${ }^{73}$ Pure germinomas are typically nonsecreting tumors, whereas nongerminomatous GCTs are secreting tumors, based on elevations of either $\alpha$-fetoprotein or HCG $\beta$ in the serum or the CSF. There is also some evidence to suggest that typical germinomas may occasionally contain foci of syncytiotrophoblastic cells, which are strongly reactive for $\mathrm{HCG} \beta$ and human placental lactogen. Placental alkaline phosphatase also appears to be a marker for intracranial germinomas. Although the clinical significance of this variant of $\mathrm{HCG} \beta$-secreting germinoma is not clearly established, as these tumors do not appear to mimic the aggressive malignant behavior of choriocarcinomas, they may be associated with a higher recurrence rate than germinomas without syncytiotro-

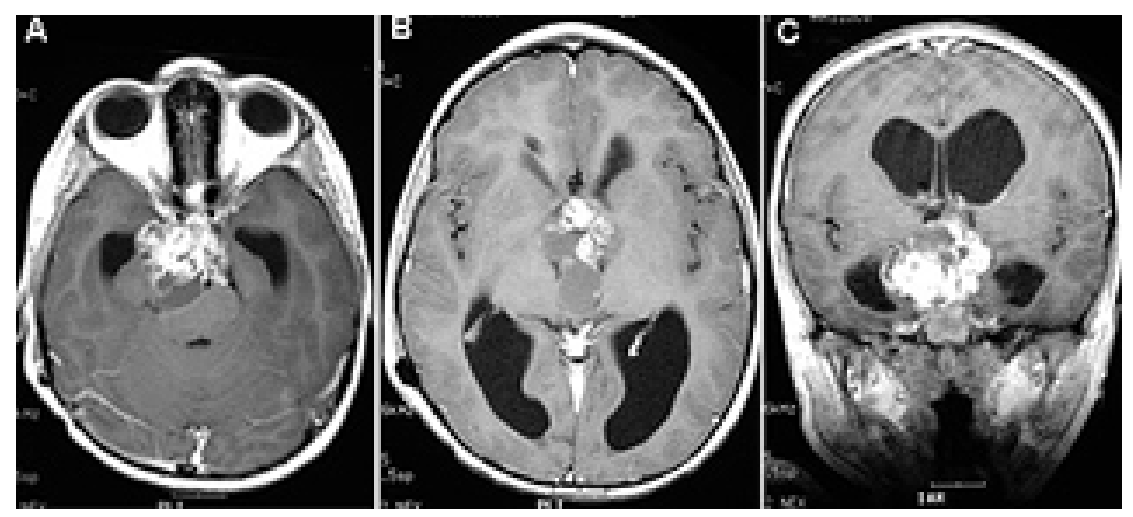

Fig. 5. Magnetic resonance imaging studies of suprasellar craniopharyngioma obtained in a patient after placement of a right ventriculoperitoneal shunt for treatment of hydrocephalus. There is a large suprasellar mass that extends into the sella, third ventricle, and into the right middle fossa to the cerebellopontine angle. The lesion displaces the chiasm anteriorly and the upper pons and midbrain dorsally, with compression of the brainstem. Precontrast $\mathrm{T}_{1}$ - and $\mathrm{T}_{2}$-weighted $\mathrm{MR}$ images (not shown) demonstrated heterogeneous signal intensity on all sequences with multiple areas of cystic change. There was extensive calcification noted. Following the adminstration of gadolium, axial (A and B), and coronal (C) $\mathrm{T}_{1}-$ weighted MR images demonstrated heterogeneous enhancment throughout the lesion and rim enhancement in several of the larger cystic regions. 
phoblastic components. ${ }^{132}$ Other authors have not found any difference in recurrence rates for $\mathrm{HCG} \beta$-secreting germinomas. ${ }^{105,112}$ Fortunately, a significant proportion of CNS GCTs can be diagnosed by analysis of tumor markers expressed in the serum or CSF or based on tissue specimens obtained by biopsy sampling or resection. Biopsy sampling of these malignant GCTs carries the inherent risk of histological sampling error, particularly in tumors with mixed elements. Serial analysis of these markers is also essential to determine and monitor treatment response. Tumor marker levels in the serum and CSF must be collected simultaneously, because it is common for normal levels to be observed in the serum while CSF levels are elevated. This finding is especially prevalent in germinomas. ${ }^{128}$ In addition, CSF specimens should be obtained from ventricular fluid intraoperatively or within 1 to 2 days postoperatively.

Because pure germinomas are extremely radiosensitive, until recently radiotherapy has remained the cornerstone of treatment. ${ }^{104,128} \mathrm{~A}$ variety of dosing schemes and volumes have been described: whole-ventricle irradiation, ${ }^{73,113}$ high-dose whole-brain irradiation, craniospinal irradiation, ${ }^{45}$ and/or low-dose irradiation to the craniospinal axis. ${ }^{46}$ Others advocate low-dose (20-24 Gy) prophylactic irradiation to the craniospinal axis in patients with positive CSF cytological findings or evidence of dissemination demonstrated on the initial MR images. ${ }^{110,111}$ In the past, it was commonplace to assess the radiosensitivity of a lesion by delivering a single fractionated dose to the tumor site, even without initially determining a diagnosis based on examination of tissue specimen. If a radiographic response was demonstrated, the tumor was considered to have germinal origin, and high-dose focal radiotherapy was initiated. ${ }^{99}$ Because of the associated long-term sequelae and morbidity of craniospinal radiotherapy in young children, however, recent strategies have been developed to avoid or reduce the role of radiotherapy in the treatment of germinomas. It has become more prevalent to initiate chemotherapy as the primary treatment for patients with CNS GCTs. Pure germinomas demonstrate an $80 \%$ complete radiographic response with chemotherapeutic regimens, regardless of the extent of tumor resection. ${ }^{128} \mathrm{~A}$ standard approach for patients in whom CNS GCTs have been diagnosed by the presence of positive tumor markers or by biopsy sample may entail initial chemotherapy followed by radiographic surveillance for residual tumor after completion of two to four cycles. A second-look surgical intervention to resect the lesion or to obtain biopsy sample is reserved for patients in whom an incomplete radiographic response is demonstrated, despite the normalization of tumor markers. ${ }^{7}$ Those who have not responded have been found to harbor either fibrotic/necrotic tissue or a teratomous lesion at secondlook surgery. ${ }^{16}$ If the teratoma is mature, excision is curative and no further therapy is indicated. If an immature teratoma is confirmed, local-field irradiation is initiated after resection. Some investigators have also suggested that radical resection of nongerminomatous GCTs may offer some survival benefit. ${ }^{7,73,128}$

Colloid Cyst. These histologically benign lesions are typically found in the roof of the third ventricle at the level of the foramen of Monro. Colloid cysts account for 15 to
$20 \%$ of all intraventricular masses and represent the most common mass lesion found in the anterior portion of the third ventricle. The histogenesis of colloid cysts remains unclear. They are rare in children, with only 1 to $2 \%$ occurring in patients younger than 10 years of age. Colloid cysts rarely become symptomatic before the patient reaches 20 years of age and are usually found in adults in the second to fourth decades of life. Clinical behavior is the same in children as adults. Symptoms of intermittent hydrocephalus are common and sudden death secondary to acute obstruction has been reported, although in the majority of cases of sudden death there appeared to be a history of symptoms indicating increasing ICP that preceded the event by weeks to months. Occasionally, acute hemorrhage within the cyst may be the presenting clinical symptom. Imaging characteristics vary depending on the contents of the cyst.

\section{Posterior Third Ventricular Masses}

A variety of tumors may arise from the region of the posterior region of the third ventricle, reflecting the varied tissue types that originate in this region. The majority of neoplasms are glial in nature (two thirds of which are usually high grade) and include astrocytomas and, to a lesser extent, ependymomas. A number of tumors arise from the pineal region and have been reviewed in preceding sections. These include the pineal region germinomas and teratomas. Pineal parenchymal tumors such as pineoblastomas, pineocytomas, and other GCTs (embryonal cell carcinomas and choriocarcinomas) are rare tumors that arise in the posterior third ventricle. Regardless of the tumor type, lesions in the posterior third ventricle cause a similar constellation of symptoms related to obstructive hydrocephalus or involvement of the pretectal plate and resulting in Parinaud syndrome.

\section{SUMMARY}

Supratentorial intraventricular lesions in children are heterogeneous with regard to tumor type and treatment. Establishing a tissue diagnosis is usually required for accurate treatment planning, and resection without adjuvant therapy can be curative in cases of selected tumor types. The tumor location, age of the patient, and imaging characteristics can help to narrow the focus of the differential diagnosis. Careful preoperative neuroimaging is extremely useful in treatment planning because a small subset of these lesions is treated expectantly.

\section{References}

1. Adamson TE, Wiestler OD, Kleihues P, et al: Correlation of clinical and pathological features in surgically treated craniopharyngiomas. J Neurosurg 73:12-17, 1990

2. Albright AL, Wisoff JH, Zeltzer P, et al: Prognostic factors in children with supratentorial (nonpineal) primitive neuroectodermal tumors. A neurosurgical perspective from the Children's Cancer Group. Pediatr Neurosurg 22:1-7, 1995

3. Al-Yamany M, Del Maestro RF: Prevention of subdural fluid collections following transcortical intraventricular and/or paraventricular procedures by using fibrin adhesive. J Neurosurg 92:406-412, 2000

4. Ashkan K, Casey AT, D'Arrigo C, et al: Benign central neurocytoma. Cancer 89:1111-1120, 2000 
5. Awaad YM, Allen JC, Miller DC, et al: Deferring adjuvant therapy for totally resected intracranial ependymoma. Pediatr Neurol 14:216-219, 1996

6. Baisden BL, Brat DJ, Melhem ER, et al: Dysembryoplastic neuroepithelial tumor-like neoplasm of the septum pellucidum: a lesion often misdiagnosed as glioma: report of 10 cases. Am J Surg Pathol 25:494-499, 2001

7. Balmaceda C, Heller G, Rosenblum M, et al: Chemotherapy without irradiation-a novel approach for newly diagnosed CNS germ cell tumors: results of an international cooperative trial. The First International Central Nervous System Germ Cell Tumor Study. J Clin Oncol 14:2908-2915, 1996

8. Baumgartner JE, Sorenson JM: Meningioma in the pediatric population. J Neurooncol 29:223-228, 1996

9. Berger C, Thiesse P, Lellouch-Tubiana A, et al: Choroid plexus carcinomas in childhood: clinical features and prognostic factors. Neurosurgery 42:470-475, 1998

10. Bergsneider M, Holly LT, Lee JH, et al: Endoscopic management of cysticercal cysts within the lateral and third ventricles. J Neurosurg 92:14-23, 2000

11. Bouffet E, Foreman N: Chemotherapy for intracranial ependymomas. Childs Nerv Syst 15:563-570, 1999

12. Boyd MC, Steinbok P: Choroid plexus tumors: problems in diagnosis and management. J Neurosurg 66:800-805, 1987

13. Brown WD, Tavare CJ, Sobel EL, et al: The applicability of Collins' Law to childhood brain tumors and its usefulness as a predictor of survival. Neurosurgery 36:1093-1096, 1995

14. Bruggers CS, Friedman HS, Phillips PC, et al: Leptomeningeal dissemination of optic pathway gliomas in three children. Am J Ophthalmol 111:719-723, 1991

15. Brzowski AE, Bazan C III, Mumma JV, et al: Spontaneous regression of optic glioma in a patient with neurofibromatosis. Neurology 42:679-681, 1992

16. Buckner JC, Peethambaram PP, Smithson WA, et al: Phase II trial of primary chemotherapy followed by reduced-dose radiation for CNS germ cell tumors. J Clin Oncol 17:933-940, 1999

17. Childhood Brain Tumor Consortium: A study of childhood brain tumors based on surgical biopsies from ten North American institutions: sample description. J Neurooncol 6:9-23, 1988

18. Chung WY, Pan DH, Shiau CY, et al: Gamma knife radiosurgery for craniopharyngiomas. J Neurosurg 93 (Suppl 3): 47-56, 2000

19. Civitello LA, Packer RJ, Rorke LB, et al: Leptomeningeal dissemination of low-grade gliomas in childhood. Neurology 38: 562-566, 1988

20. Coulon RA, Till K: Intracranial ependymomas in children: a review of 43 cases. Childs Brain 3:154-168, 1977

21. Crotty TB, Scheithauer BW, Young WF Jr, et al: Papillary craniopharyngioma: a clinicopathological study of 48 cases. J Neurosurg 83:206-214, 1995

22. Deen HG Jr, Scheithauer BW, Ebersold MJ: Clinical and pathological study of meningiomas of the first two decades of life. J Neurosurg 56:317-322, 1982

23. De Vile CJ, Grant DB, Kendall BE, et al: Management of childhood craniopharyngioma: can the morbidity of radical surgery be predicted? J Neurosurg 85:73-81, 1996

24. Diaz P, Maillo A, Morales F, et al: Multiple meningiomas of the fourth ventricle in infancy: case report. Neurosurgery 26: 1057-1060, 1990

25. Di Rocco C, Iannelli A, Marchese E: On the treatment of subependymal giant cell astrocytomas and associated hydrocephalus in tuberous sclerosis. Pediatr Neurosurg 23: 115-121, 1995

26. Due-Tonnessen B, Helseth E, Skullerud K, et al: Choroid plexus tumors in children and young adults: report of 16 consecutive cases. Childs Nerv Syst 17:252-256, 2001

27. Duff JM, Meyer FB, Ilstrup DM, et al: Long-term outcomes for surgically resected craniopharyngiomas. Neurosurgery 46: 291-305, 2000
28. Duffner PK, Cohen ME, Horowitz M, et al: The treatment of choroid plexus carcinoma in infancy with chemotherapy. Ann Neurol 26:460, 1989 (Abstract)

29. Duffner PK, Kun LE, Burger PC, et al: Postoperative chemotherapy and delayed radiation in infants and very young children with choroid plexus carcinomas. The Pediatric Oncology Group. Pediatr Neurosurg 22:189-196, 1995

30. Ellenbogen RG, Winston KR, Kupsky WJ: Tumors of the choroid plexus in children. Neurosurgery 25:327-335, 1989

31. Eng DY, DeMonte F, Ginsberg L, et al: Craniospinal dissemination of central neurocytoma. Report of two cases. J Neurosurg 86:547-552, 1997

32. Enomoto H, Mizuno M, Katsumata T, et al: Intracranial metastasis of a choroid plexus papilloma originating in the cerebellopontine angle region: a case report. Surg Neurol 36:54-58, 1991

33. Ernestus RI, Schroder R, Stutzer H, et al: Prognostic relevance of localization and grading in intracranial ependymomas of childhood. Childs Nerv Syst 12:522-526, 1996

34. Ferrante L, Acqui M, Artico M, et al: Cerebral meningiomas in children. Childs Nerv Syst 5:83-86, 1989

35. Fischer EG, Welch K, Shillito J Jr, et al: Craniopharyngiomas in children. Long-term effects of conservative surgical procedures combined with radiation therapy. J Neurosurg 73: 534-540, 1990

36. Flickinger JC, Lundsford LD, Singer J, et al: Megavoltage external beam irradiation of craniopharyngiomas: analysis of tumor control and morbidity. Int J Radiat Oncol Biol Phys 19: 117-122, 1990

37. Forsyth PA, Shaw EG, Scheithauer BW, et al: Supratentorial pilocytic astrocytomas. A clinicopathologic, prognostic, and flow cytometric study of 51 patients. Cancer 72:1335-1342, 1993

38. Gaab MR, Schroeder HW: Neuroendoscopic approach to intraventricular lesions. J Neurosurg 88:496-505, 1998

39. Gaffney CC, Sloane JP, Bradley NJ, et al: Primitive neuroectodermal tumours of the cerebrum. J Neurooncol 3:23-33, 1985

40. Goldwein JW, Corn BW, Finlay JL, et al: Is craniospinal irradiation required to cure children with malignant (anaplastic) intracranial ependymomas? Cancer 67:2766-2771, 1991

41. Goldwein JW, Leahy JM, Packer RJ, et al: Intracranial ependymomas in children. Int J Radiat Oncol Biol Phys 19: 1497-1502, 1990

42. Greenberg ML: Chemotherapy of choroid plexus carcinoma. Childs Nerv Syst 15:571-577, 1999

43. Habrand JL, Ganry O, Couanet D, et al: The role of radiation therapy in the management of craniopharyngioma: a 25 year experience and review of the literature. Int $\mathbf{J}$ Radiat Oncol Biol Phys 44:255-263, 1999

44. Haddad SF, Menezes AH, Bell WE, et al: Brain tumors occurring before 1 year of age: a retrospective review of 22 cases in an 11-year period (1977-1987). Neurosurgery 29:8-13, 1991

45. Haddock MG, Schild SE, Scheithauer BW, et al: Radiation therapy for histologically confirmed primary central nervous system germinoma. Int J Radiat Oncol Biol Phys 38:915-923, 1997

46. Hardenbergh PH, Golden J, Billet A, et al: Intracranial germinoma: the case for lower dose radiation therapy. Int J Radiat Oncol Biol Phys 39:419-426, 1997

47. Hayward R: The present and future management of childhood craniopharyngioma. Childs Nerv Syst 15:764-769, 1999

48. Healey EA, Barnes PD, Kupsky WJ, et al: The prognostic significance of postoperative residual tumor in ependymoma. Neurosurgery 28:666-672, 1991

49. Helseth A, Mork SJ: Neoplasms of the central nervous system in Norway. III. Epidemiological characteristics of intracranial gliomas according to histology. APMIS 97:547-555, 1989

50. Helseth E, Due-Tonnessen B, Lote K, et al: Ependymoma in children and young adults ( $0-19$ years): report of 25 consecutive cases. Childs Nerv Syst 17:24-30, 2001 
51. Herz DA, Shapiro K, Shulman K: Intracranial meningiomas of infancy, childhood and adolescence. Review of the literature and addition of 9 case reports. Childs Brain 7:43-56, 1980

52. Hirsch JF, Sainte-Rose C: A new surgical approach to subcortical lesions: balloon inflation and cortical gluing. Technical note. J Neurosurg 74:1014-1017, 1991

53. Hoffman HJ, De Silva M, Humphreys RP, et al: Aggressive surgical management of craniopharyngiomas in children. J Neurosurg 76:47-52, 1992

54. Hope JKA, Armstrong DA, Babyn PS et al: Primary meningeal tumors in children: correlation of clinical and CT findings with histologic type and prognosis. AJNR 13:1353-1364, 1992

55. Horn B, Heideman R, Geyer R, et al: A multi-institutional retrospective study of intracranial ependymoma in children: identification of risk factors. J Pediatr Hematol Oncol 21: 203-211, 1999

56. Hukin J, Epstein F, Lefton D, et al: Treatment of intracranial ependymoma by surgery alone. Pediatr Neurosurg 29:40-45, 1998

57. Hunt SJ, Johnson PC, Coons SW, et al: Neonatal intracranial teratomas. Surg Neurol 34:336-342, 1990

58. Jakacki RI: Pineal and nonpineal supratentorial primitive neuroectodermal tumors. Childs Nerv Syst 15:586-591, 1999

59. Janss AJ, Grundy R, Cnaan A, et al: Optic pathway and hypothalamic/chiasmatic gliomas in children younger than age 5 years with a 6-year follow-up. Cancer 75:1051-1059, 1995

60. Jayawickreme DP, Hayward RD, Harkness WF: Intracranial ependymomas in childhood: a report of 24 cases followed for 5 years. Childs Nerv Syst 11:409-413, 1995

61. Jelinek J, Smirniotopoulos JG, Parisi JE, et al: Lateral ventricular neoplasms of the brain: Differential diagnosis based on clinical, CT, and MR findings. AJNR 11:567-574, 1990

62. Kim DG, Paek SH, Kim IH, et al: Central neurocytoma: the role of radiation therapy and long term outcome. Cancer 79: 1995-2002, 1997

63. Lee YY, Van Tassel P, Bruner JM, et al: Juvenile pilocytic astrocytomas: CT and MR characteristics. AJR 152: 1263-1270, 1989

64. Legido A, Packer RJ, Sutton LN, et al: Suprasellar germinomas in childhood. A reappraisal. Cancer 63:340-344, 1989

65. Levy ML, Goldfarb A, Hyder DJ, et al: Choroid plexus tumors in children: Significance of stromal invasion. Neurosurgery 48:303-309, 2001

66. Listernick R, Charrow J, Greenwald M, et al: Natural history of optic pathway tumors in children with neurofibromatosis type 1: a longintudinal study. J Pediatr 125:63-66, 1994

67. Listernick R, Louis DN, Packer RJ, et al: Optic pathway gliomas in children with neurofibromatosis 1: consensus statement from the NF1 Optic Pathway Glioma Task Force. Ann Neurol 41:143-149, 1997

68. Lunsford LD, Pollack BE, Kondziolka DS, et al: Stereotactic options in the management of craniopharyngiomas. Pediatr Neurosurg 21:90-97, 1994

69. Lyons MK, Kelly PJ: Posterior fossa ependymomas: report of 30 cases and review of the literature. Neurosurgery 28: 659-665, 1991

70. Maira G, Anile C, Colosimo C, et al: Craniopharyngiomas of the third ventricle: trans-lamina terminalis approach. Neurosurgery 47:857-865, 2000

71. Mallucci CL, Parkes SE, Barber P, et al: Paediatric meningeal tumors. Childs Nerv Syst 12:582-588, 1996

72. Mamelak AN, Prados MD, Obana WG, et al: Treatment options and prognosis for multicentric juvenile pilocytic astrocytoma. J Neurosurg 81:24-30, 1994

73. Matsutani M, Sano K, Takakura K, et al: Primary intracranial germ cell tumors: a clinical analysis of 153 histologically verified cases. J Neurosurg 86:446-455, 1997

74. McComb JG. Comment on Sutton LN, Golden JA, Needle M, et al: Surgical removal of a choroid plexus adenoma using the argon beam coagulator: technical case report. Neurosurgery 43:171-174, 1998

75. McConachie NS, Worthington BS, Cornford EJ, et al: Review article: computed tomography and magnetic resonance in the diagnosis of intraventricular cerebral masses. Br J Radiol 67: 223-243, 1994

76. McEvoy AW, Harding BN, Phipps KP, et al: Management of choroid plexus tumors in children: 20 years experience at a single neurosurgical centre. Pediatr Neurosurg 32:192-199, 2000

77. McGirr SJ, Ebersold MJ, Scheithauer BW, et al: Choroid plexus papillomas: long-term follow-up results in a surgically treated series. J Neurosurg 69:843-849, 1988

78. Merchant TE, Haida T, Wang MH, et al: Anaplastic ependymoma: treatment of pediatric patients with or without craniospinal radiation therapy. J Neurosurg 86:943-949, 1997

79. Morita A, Kelly PJ: Resection of intraventricular tumors via a computer-assisted volumetric stereotactic approach. Neurosurgery 32:920-927, 1993

80. Morrison G, Sobel DF, Kelley WM, et al: Intraventricular mass lesions. Radiology 53:435-442, 1984

81. Nabbout R, Santos M, Rolland Y, et al: Early diagnosis of subependymal giant cell astrocytoma in children with tuberous sclerosis. J Neurol Neurosurg Psychiatry 66:370-375, 1999

82. Nagib MG, Haines SJ, Erickson DL, et al: Tuberous sclerosis: a review for the neurosurgeon. Neurosurgery 14:93-98, 1984

83. Nazar GB, Hoffman HJ, Becker LE, et al: Infratentorial ependymomas in childhood: Prognostic factors and treatment. J Neurosurg 72:408-417, 1990

84. Needle MN, Goldwein JW, Grass J, et al: Adjuvant chemotherapy for the treatment of intracranial ependymoma of childhood. Cancer 80:341-347, 1997

85. Osborn AG: Diagnostic Neuroradiology. St. Louis: Mosby, 1994, pp 401-528

86. O'Sullivan C, Jenkin RD, Doherty MA, et al: Spinal cord tumors in children: long-term results of combined surgical and radiation treatment. J Neurosurg 81:507-512, 1994

87. Palma L, Celli P, Cantore G: Supratentorial ependymomas of the first two decades of life. Long-term follow-up of 20 cases (including two subependymomas). Neurosurgery 32:169-175, 1993

88. Palma L, Celli P, Mariottini A, et al: The importance of surgery in supratentorial ependymomas. Long-term survival in a series of 23 cases. Childs Nerv Syst 16:170-175, 2000

89. Palma L, Guidetti B: Cystic pilocytic astrocytomas of the cerebral hemispheres. Surgical experience with 51 cases and longterm results. J Neurosurg 62:811-815, 1985

90. Pencalet P, Sainte-Rose C, Lellouch-Tubiana A, et al: Papillomas and carcinomas of the choroid plexus in children. $\mathbf{J}$ Neurosurg 88:521-528, 1998

91. Pendl G, Ozturk E, Haselsberger K: Surgery of tumors of the lateral ventricle. Acta Neurochir 116:128-136, 1992

92. Piepmeier JM: Tumors and approaches to the lateral ventricles. Introduction and overview. J Neurooncol 30:267-274, 1996

93. Pierre-Kahn A, Hirsch JF, Roux FX, Ronier D, Sainte-Rose C: Intracranial ependymomas in childhood. Survival and functional results of 47 cases. Childs Brain 10:145-156, 1983

94. Pollack IF, Gerszten PC, Martinez AJ, et al: Intracranial ependymomas of childhood: long-term outcome and prognostic factors. Neurosurgery 37:655-667, 1995

95. Raco A, Raimondi AJ, D'Alonzo A, et al: Radiosurgery in the management of pediatric brain tumors. Childs Nerv Syst 16:287-295, 2000

96. Raimondi AJ, Rogerie J: A critical review of personal experiences with craniopharyngioma: clinical history, surgical technique and operative results. 1983. Pediatr Neurosurg 21: 134-154, 1994

97. Rajan B, Ashley S, Gorman C, et al: Craniopharyngioma-a long-term results following limited surgery and radiotherapy. Radiother Oncol 26:1-10, 1993 
98. Reddy AT, Packer RJ: Chemotherapy for low-grade gliomas. Childs Nerv Syst 15:506-513, 1999

99. Rich TA, Cassady JR, Strand RD, et al: Radiation therapy for pineal and suprasellar germ cell tumors. Cancer 55:932-940, 1985

100. Robertson PL, Zeltzer PM, Boyett JM, et al: Survival and prognostic factors following radiation therapy and chemotherapy for ependymomas in children: a report of the Children's Cancer Group. J Neurosurg 88:695-703, 1998

101. Rodriguez LA, Edwards MS, Levin VA: Management of hypothalamic gliomas in children: an analysis of 33 cases. Neurosurgery 26:242-247, 1990

102. Roszkowski M, Drabik K, Barszcz S, et al: Surgical treatment of intraventricular tumors associated with tuberous sclerosis. Childs Nerv Syst 11:335-339, 1995

103. Rush JA, Younge BR, Campbell RJ, et al: Optic glioma. Long term follow-up of 85 histopathologically verified cases. Ophthalmology 89: 1213-1219, 1982

104. Sawamura Y, de Tribolet N, Ishii N, et al: Management of primary intracranial germinomas: diagnostic surgery or radical resection? J Neurosurg 87:262-266, 1997

105. Sawamura Y, Shirato H, Ikeda J, et al: Induction chemotherapy followed by reduced-volume radiation therapy for newly diagnosed central nervous system germinoma. J Neurosurg 88:66-72, 1998

106. Scott RM, Hetelekidis S, Barnes PD, et al: Surgery, radiation, and combination therapy in the treatment of childhood craniopharyngiomas - a 20-year experience. Pediatr Neurosurg 21:75-81, 1994

107. Sgouros S, Jackowski A, Carey MP: Central neurocytoma without intraventricular extension. Surg Neurol 42:335-339, 1994

108. Shaw EG, Evans RG, Scheithauer BW, et al: Postoperative radiotherapy of intracranial ependymoma in pediatric and adult patients. Int J Radiat Oncol Biol Phys 13:1457-1462, 1987

109. Shepherd CW, Scheithauer B, Gomez MR: Brain tumors in tuberous sclerosis. A clinicopathologic study of the Mayo Clinic experience. Ann NY Acad Sci 615:378-379, 1991

110. Shibamoto Y, Abe M, Yamashita J, et al: Treatment results of intracranial germinoma as a function of the irradiated volume. Int J Radiat Oncol Biol Phys 15:285-290, 1988

111. Shibamoto Y, Oda Y, Yamashita J, et al: The role of cerebrospinal fluid cytology in radiotherapy planning for intracranial germinoma. Int J Radiat Oncol Biol Phys 29:1089-1094, 1994

112. Shibamoto Y, Takahashi M, Sasai K: Prognosis of intracranial germinoma with syncytiotrophoblastic giant cells treated by radiation therapy. Int J Radiat Oncol Biol Phys 37:505-510, 1997

113. Shirato H, Nishio M, Sawamura Y, et al: Analysis of longterm treatment of intracranial germinoma. Int J Radiat Oncol Biol Phys 37:511-515, 1997

114. Sim KB, Hong SK: Multicentric juvenile pilocytic astrocytoma occurring primarily in the trigone of the lateral ventricle. Childs Nerv Syst 15:477-481, 1999

115. Souweidane MM, Johnson JH Jr, Lis E: Volumetric reduction of a choroid plexus carcinoma using preoperative chemotherapy. J Neurooncol 43:167-171, 1999

116. St Clair SK, Humphreys RP, Pillay PK, et al: Current management of choroid plexus carcinoma in children. Pediatr Neurosurg 17:225-233, 1991-92
117. Strong JA, Hatten HP Jr, Brown MT, et al: Pilocytic astrocytoma: correlation between the initial imaging features and clinical aggressiveness. AJR 161:369-372, 1993

118. Sugiyama K, Uozumi T, Kiya K, et al: Intracranial germ-cell tumor with synchronous lesions in the pineal and suprasellar regions: report of six cases and review of the literature. Surg Neurol 38:114-120, 1992

119. Sutton LN, Golden JA, Needle M, et al: Surgical removal of a choroid plexus adenoma using the argon beam coagulator: Technical case report. Neurosurgery 43:171-173, 1998

120. Sutton LN, Goldwein J, Perilongo G, et al: Prognostic factors in childhood ependymomas. Pediatr Neurosurg 16:57-65, 1990-1991

121. Sutton LN, Molloy PT, Sernyak H, et al: Long-term outcome of hypothalamic/chiasmatic astrocytomas in children treated with conservative surgery. J Neurosurg 83:583-589, 1995

122. Symon L, Sprich W: Radical excision of craniopharyngiomas. Results in 20 patients. J Neurosurg 62:174-181, 1985

123. Tatter SB, Borges LF, Louis DN: Central neurocytomas of the cervical spinal cord. Report of two cases. J Neurosurg 81: 288-293, 1994

124. Tien RD: Intraventricular mass lesions of the brain: CT and MRI findings. AJR 157:1283-1290, 1991

125. Turgut M, Ozcan OE, Bertan V: Meningiomas in childhood and adolescence: a report of 13 cases and review of the literature. Br J Neurosurg 11:501-507, 1997

126. Waldron JN, Laperriere NJ, Jaakkimainen L, et al: Spinal cord ependymomas: a retrospective analysis of 59 cases. Int J Radiat Oncol Biol Phys 27:223-229, 1993

127. Wallner KE, Gonzales MF, Edwards MS, et al: Treatment results of juvenile pilocytic astrocytoma. J Neurosurg 69: 171-176, 1988

128. Weiner HL, Finlay JL: Surgery in the management of primary intracranial germ cell tumors. Childs Nerv Syst 15:770-773, 1999

129. Weiss M, Sutton L, Marcial V, et al: The role of radiotherapy in the management of childhood craniopharyngioma. Int $\mathbf{J}$ Radiat Oncol Biol Phys 17:1313-1321, 1989

130. Whitaker SJ, Bessell EM, Ashley SE, et al: Postoperative radiotherapy in the management of spinal cord ependymoma. J Neurosurg 74:720-728, 1991

131. Yaşargil MG, Curcic M, Kis M, et al: Total removal of craniopharyngiomas. Approaches and long-term results in 144 patients. J Neurosurg 73:3-11, 1990

132. Yoshida J, Sugita K, Kobayashi T, et al: Prognosis of intracranial germ cell tumours: effectiveness of chemotherapy with cisplatin and etoposide (CDDP and VP-16). Acta Neurochir 120:111-117, 1993

133. Zuccaro G, Sosa F, Cuccia V, et al: Lateral ventricle tumors in children: a series of 54 cases. Childs Nerv Syst 15:774-785, 1999

Manuscript received May 2, 2001.

Accepted in final form May 25, 2001.

Address reprint requests to: Timothy Mapstone, M.D., Department of Neurosurgery, Emory University School of Medicine, 1365-B Clifton Road, North East, Suite 6400, Atlanta, Georgia 30322, email: timothy_mapstone@emory.org. 